Elizabeth Bolton*

\title{
Meaning-making across disparate realities: A new cognitive model for the personality-integrating response to fairy tales
}

DOI 10.1515/sem-2015-0141

Abstract: This paper reviews the extant literature on ways readers make meaning from fairy tales, and proposes a new cognitive model for the response to the traditional fairy tale. Much of the available research on literary responses to fairy tales comes from within the boundaries of psychoanalysis (Bettelheim 1975. The uses of enchantment: The meaning and importance of fairy tales. New York: Vintage; Dieckmann 1986. Twice-told tales: The psychological use of fairy tales. Wilmette: Chiron; Miller 1984. Thou shalt not be aware: Society's betrayal of the child. New York: Farrar, Straus, Giroux), as well as folklore studies and anthropology (Zipes 1983. Fairy tales and the art of subversion: The classical genre for children and the process of civilization. New York: Wildman Press; Zipes 2006. Why fairy tales stick: The evolution and relevance of a genre. New York: Routledge; Zipes 2012. The irresistible fairy tale: The cultural and social history of a genre. Princeton: Princeton University Press.). Although these fields do not often overlap, the therapeutic potential of fairy tales and relatively recent popularization of practices such as bibliotherapy (Jack and Ronan 2008. Bibliotherapy: Practice and research. School Psychology International 29(2). 161-182) have provided a fertile ground for linking the two disciplines. I propose a cognitive model for the emotionally integrating response to the fairy tale by first introducing Rosenblatt's (1978. The reader, the text, the poem. Carbondale: Southern Illinois University Press) transactional theory of making meaning from literature, and then in light of this theory, reviewing the psychoanalytic and anthropological evidence for fairy tales' unique effect on readers. Previous theories explaining the emotional benefits of reading fairy tales have failed to consider characteristics of the genre which are unique to it, and which give fairy tales a hierarchically higher status than other genres due to the distance between the reality they depict, and the current reality of the reader. Transactional theory indicates that this higher status may play a crucial role in

*Corresponding author: Elizabeth Bolton, OISE, CTL, LLE, University of Toronto, 252 Bloor St. West 10-271, Toronto, ON M5S 1V6, Canada, E-mail: e.bolton@mail.utoronto.ca 
the genre's ability to support healthy emotional development, as readers who establish close personal connections with the hierarchically valorized genre actually become active participants in a reading experience which provides them with comforting, indisputable affirmation of the uprightness of their own moral principles.

Keywords: fairy tales, traditional literature, transactional theory

This paper reviews the extant literature on ways readers make meaning from fairy tales, and proposes a novel cognitive model for the reader's response to the traditional fairy tale. Much of the available research on literary responses to fairy tales comes from within the boundaries of psychoanalysis (Bettelheim 1975; Dieckmann 1986; Miller 1984), as well as folklore studies and anthropology (Zipes 1983, 2006, 2012). Although these fields do not often overlap, the therapeutic potential of fairy tales and relatively recent popularization of practices such as bibliotherapy (Jack and Ronan 2008) have provided a fertile ground for linking the two disciplines. I propose a cognitive model for the emotionally integrating response to the fairy tale by first introducing Rosenblatt's (1978) transactional theory of making meaning from literature, and then in light of this theory, reviewing the psychoanalytic and anthropological evidence for fairy tales' unique effect on readers. Previous theories explaining the emotional benefits of reading fairy tales have failed to consider characteristics of the genre which are unique to it, and which give fairy tales a hierarchically higher status than other genres due to the distance between the reality they depict, and the current reality of the reader. Transactional theory indicates that this higher status may play a crucial role in the genre's ability to support healthy emotional development, as readers who establish close personal connections with the hierarchically valorized genre actually become active participants in a reading experience which provides them with comforting, indisputable affirmation of the uprightness of their own moral principles.

As the concept of the emotionally supportive fairy tale begins with the interaction between the reader's reality and reality depicted in the literature, I will begin with an overview of the two realities which collide during the reading of a fairy tale (Zipes 2012), followed by an introduction to the transactional theory of literary response as it may be applied to the phenomenon of the therapeutic fairy tale.

\section{A transaction between realities}

Traditional literature has long been known as a genre which comforts readers with its offer of escape from contemporary reality. We seem to treasure fairy 
tales for the distance between realities they suggest, and set them in their own special category as a result, apart from other types of fiction. To be sure, fiction in general offers an escape from every day life, but if this escape is found to be emotionally supportive by some readers, why is it that fairy tales are the only fictional genre to have been widely used in therapeutic settings? Is the distance between current reality and fairy tale reality somehow comforting to readers? What happens when we allow ourselves as readers to become immersed in a reality which, instead of existing alongside our own, is inaccessible by humans? Further, what happens to our perceptions of our own reality when we make meaning from a text depicting reality of hierarchically higher status? In order to understand why the act of making meaning from a fairy tale is possibly therapeutic and unlike the act of making meaning from any other genre, it is necessary first to understand the nature of the distance between reader reality and fairy tale reality, and second, to examine in depth the transactional process of making a distant reality meaningful.

\subsection{Distance between realities}

Unlike the realistic fictional novel, which depicts "reality itself in the process of its unfolding," (Bakhtin 1981: 7) there are certain genres of fiction which depict a closed reality, a reality which stands "beyond the realm of human activity" (Bakhtin 1981: 17). Bakhtin (1981) identified the national epic as belonging to such a genre, and I propose to place the fairy tale in the same category. With both the epic and the fairy tale, the reader is aware that author and reader do not exist in the same time and place. The fairy tale reality exists on an entirely different temporal plane, one separated from the current time by a great distance. This distance acts as a boundary between realities, and isolates the fairy tale world "from personal experience, from any new insights, from any personal initiative in understanding and interpreting, from new points of view and evaluations" (Bakhtin 1981: 17).

As an idea, the fairy tale past is conclusive and immutable, which gives special magnetic force to the messages it conveys, for their validity cannot at this point be revaluated. Fairy tale events therefore play out as "truths rather than likelihoods, as prophecies rather than predictions," (Bakhtin 1981: 17) and as a result readers are compelled to bestow upon the fairy tale's messages a greater reverence than they would other genres of fiction. Even the events and characters found in the tales receive high value and grandeur through their association with an untouchable past. 
As they are removed from the indecision of the current reality, fairy tale events and characters assume a "finished quality" in their existence upon a valorized temporal plane (Bakhtin 1981: 18). That we should hold them in higher esteem than the current reality, still raw in its process of unfolding, is without question. What happens, then, when a reader establishes a strong personal connection with events and characters from an "utterly finished," closed reality? Transactional theory states that readers construct meaning from texts using personal memories, associations and feelings as building blocks (Rosenblatt 1978). I suggest that in using personal material to construct meaning from a genre depicting a closed reality, readers who establish strong personal connections with fairy tales will find their own perceptions of reality transformed as a result. This transformation shifts perceptions of personal reality in such a way that, in some readers, results in emotional integration. Below, I will outline Rosenblatt's transactional theory of literary response for an enhanced understanding of how readers interact with closed, finished realities during the meaning making process, and how this interaction may result in emotional integration.

\subsection{A transaction between realities}

In order to understand why fairy tales are continually taken seriously in therapeutic settings, one might begin by examining how the reader interacts with a text in the general sense. How might this transaction, in which the reader acts on the text insofar as the text acts on the reader, actually become therapeutic? How might it help her to manage emotions which have until now been overwhelming, too difficult to face and process? In answering these questions and others, I will adopt an experiential stance towards the theory of literary response, and focus on the reader's processes of engagement and involvement in composing her own meaning from a text (Beach 1993).

\subsection{Efferent versus aesthetic reading}

I will begin with the assumption that if the reading of a text somehow changes the reader's perception of certain aspects of her own life, then she must have taken some kind of active, personalized role in responding to the literature and creating meaning from it. Rosenblatt's work focuses on this active, creative role of the reader in response to patterned textual symbols on the page (i. e., the text itself), and it is her transactional theory which serves as the basis for the 
proposed model of how fairy tales support healthy emotional development in an interactional manner.

According to Rosenblatt (1978), readers read in any combination of two possible ways which exist at opposite ends of a continuum, each of which I will define here briefly so that it may be understood in juxtaposition with the other. These two types are efferent, and aesthetic reading. Efferent reading, Rosenblatt says, derives its name from the present participial form of the Latin verb efferre, meaning "to carry out." An efferent reading of a text results in just that - a carrying out of information from the text for later use. Note than any text may be read efferently, so long as the reader chooses to read it in this way. Quite often, reading comprehension textbook questions (e. g., "What information do you learn about Fern's family from this chapter?”) almost guarantee an efferent reading as they set the reader up, first and foremost, to scan for the requested information. In an efferent reading, the auditory characteristics of words need not even be dealt with, as readers may immediately make associations between visual characteristics of words and meanings of them for quick, practical purposes (Rosenblatt 1978). Efferent reading scavenges the textual surface of literature and serves the valuable purpose of retaining important information for later use or contemplation, as anyone who has ever read a recipe for a chicken marinade or directions for assembling furniture well knows.

Aesthetic reading, at the other end of the reader-response continuum, focuses not on what is to be carried out of the reading, but on the act of reading itself, specifically the feelings and associations stirred up within the reader in response to the words (Rosenblatt 1978). An aesthetic reading of a text is truly transactional in that the text performs action on the reader insofar as the reader performs action on the text. In an aesthetic reading, personal memories, associations and feelings are supplied for the construction of meaning in a manner gently guided by the text as stimulus, creating a suitable environment for a therapeutic reading experience. Unlike efferent reading, the auditory characteristics of words cannot be bypassed in an aesthetic reading, for even the very metering and rhyme of them stirs up certain attitudes in the reader.

As with efferent reading, whether a text is read aesthetically or not depends on the action of the reader, although certain texts will clearly more readily orient the reader to take one stance over the other. If a reading of Hansel and Gretel is assigned and prefaced with comprehension questions such as, "Which two methods does Hansel use to try to find his way back home from the forest?" or "How do Hansel and Gretel escape from the witch?" a reader will likely orient herself efferently, knowing that she will be held responsible for knowing the answers to these questions after reading. If the same reader happens to flip open 
an old volume of fairy tales to Hansel and Gretel on a rainy Sunday afternoon and curl up on the couch to read it, her stance will likely be aesthetic, as she will patiently savor the experience of reading the story with no expectation of testing to follow. Her aesthetic reading will allow her the space to construct meaning from her own associations, the selection of which will be guided by the textual symbols found in the literature. In this transactional way, the aesthetic reader acts on the text in supplying her own material for making meaning, while the text acts on the reader in guiding her to make the most relevant choices.

\subsubsection{The fusion of thought and feeling}

As an aesthetic reading of a text requires both continual awareness of textual symbols, as well as constant selection of personal associations, it is an experience that can be said to "fus[e] the cognitive and the emotive, or perhaps more accurately, apprehen[d] them as facets of the same lived-through experience” (Rosenblatt 1978: 46). Rosenblatt (1983) has long suggested that literature may provide ideal linkage between thought, feeling and even behavior. Aesthetic reading permits us to think and feel at the same time, and in doing so, permits the emotional mind to function rationally alongside its emotive characteristics.

The aesthetic stance towards a text can thus be called constructive in that it asks the reader to simultaneously read and "pay attention to all of the elements activated within him by the text” (Rosenblatt 1978: 46), thereby creating an avenue by which the fusion of cognitive and emotive may take place. In certain cases, this fusion can facilitate a re-narration of memories, stripping away lingering elements of self-doubt, denial and fear and leaving the memory with a new corresponding emotion. This new emotion (compassion for oneself in place of shame at the memory of a traumatic event, for example) will have been suggested by the textual patterns of the literature, as well as affirmed from an ethical standpoint as adhering to a set of moral principles to which all humans, by sensual nature, gravitate (Jolles 1972). In the case of someone who has suffered psychological trauma, affirmation of the validity of one's own pain can be immensely powerful. Linking emotions with memories, and having those emotional-cognitive fusions affirmed by hierarchically valorized literature is what permits those memories to settle into harmonious place in the overall narrative of personal lives. It is the active guidance of the fairy tale and its treatment of morality which ushers heretofore painful, disintegrated memories into harmonious place within an integrated personality. 
Under the force of the interaction with the fairy tale, the personal reality of the reader is transmuted, and the uprightness of one's sense of morality is confirmed. As Rosenblatt (1978: 34) puts it, "[i]n the reading relationship, the reader brings his sense of something called reality, to which words point; this may become transmuted into something 'rich and strange' under the magnetism of the patterned words of the text." As we will see, the "magnetism" of fairy tales is extraordinarily strong.

\subsection{The dual stream of response}

As the aesthetic reader supplies her own personal associations (whether consciously selected or not) in response to the pattern of symbols on the page, she becomes actively engaged in a meaning-making reading experience which results in what Rosenblatt calls "the evocation of a work of art" (1978: 27). The evoked work of art (or "poem" as Rosenblatt termed it) arises as a direct result of the reader's continued stream of associations due to a heightened, continued awareness of text, and is therefore the unique creation of the reader herself. As it unfolds, the poem itself becomes a focal point of the reader, who engages in what Rosenblatt calls "aesthetic contemplation" or "what the perceiver makes of his [or her] own responses to the artistic stimulus" (1978: 31).

An aesthetic reading is therefore an active transaction between reader and text, resulting in two streams of response, the first in response to the text as stimuli, and the second in contemplative response to that which the text has evoked for the reader. The secondary, contemplative response is, in essence, a meditation on one's own creation of meaning. As a result, this act of reflection on one's own creation, built in to the transactional model of reading, sets the stage for self-reflection in the reader. Rosenblatt writes that "[e]ven as we are generating a work of art, we are reacting to it” (1978: 48). When literature stirs something in us, when we feel that we have deeply understood it by virtue of the knowledge we have brought to the table in our interactions with it, we very naturally develop another, secondary response to that meaning which is often, but not always, subconscious. Rosenblatt (1978) elaborates:

This dual stream of responses may not always be apprehended as separate. The reaction to the emerging work may be felt merely as a general state of mind, an ambiance of acceptance, approval, incredulity. Such responses may be momentary, peripheral, almost woven into the texture of what is felt to be the work itself. Or the reaction may at times take more conscious form. The range of potential responses and the gamut of degrees of intensity and articulateness are infinitely vast, since they depend not only on the character of the text but even more on the special character of the individual reader. (Rosenblatt 1978: 49) 
This secondary reaction to our own evoked response may be of any nature at all, as it is dependent on the character of the individual, and often perceived as simply the general sense one gets from reading the literature. What is less obvious to most readers is that the secondary reaction, in addition to coming across as a "general sense" or feeling, is an act of self-reflection, as it has arisen in response to a work of art which could not have come into being without the reader's personal experiences and associations. In fact, the work of art is literally composed of the reader's personal experiences and associations, thus what the reader responds to is essentially her very own self. How, then, does a response to our own feelings and associations constitute a scaffolding of healthy emotional growth? Of what nature must this response be, in order for emotional development to truly be supported?

In order for literature to provide us with any sense of comfort, our reaction to the emerging sense of personalized meaning from a reading experience must be one of acceptance, or affirmation. Affirmation reassures us that we have the right to fuse certain emotions with certain acts of cognition, where before we may have tried to deny or suppress these fusions due to the discomfort they entailed (Janson and King 2006). Affirmation of feelings of dislike for one's mother from reading about a character who is similarly mistreated by her mother might occur in the following manner: A reader who has had particular difficulty dealing with a sociopathic mother who denies her child independence, perhaps enabling infantile behavior or overfeeding, may draw on this personal experience when constructing the witch from the Grimms' Hansel and Gretel. The fairy tale, with its unique treatment of moral principles, does readers the favor of making indisputably clear that the witch's intentions of kidnapping the children, fattening them up and eating them are morally wrong. There is no question in any reader's mind, nor has there ever been for as long as this tale has survived and propagated, that to feel anger towards the witch is entirely healthier than to feel love for her. The reader, having constructed this meaning from the tale using her personal memories as building blocks, evokes a work of art which has been guided by the textual direction of the fairy tale, but which is composed of her own personal associations, and highly relevant ones in her case. The emotions of anger or frustration become fused with the acts of cognition surrounding these personal memories, and now, as a result of the high value placed on the reality of the fairy tale, any doubt that these emotions should accompany such thoughts is eliminated. As a result, the reader feels a response to her own evoked meaning characterized by acceptance. If the closed, indisputable reality of the fairy tale states that spoiling a child and denying her independence is cruel, then the reader's acceptance of that sentiment is further strengthened by the high status of the fairy tale, and consequently, the 
high status of its message. Where before she might have felt guilt in feeling angry towards her mother's actions, leaving her in a state of emotional denial and discord, the reader now finds herself in a state of agreement with her own reaction, in large part supported by the fairy tale's universally accepted, timetested, sensually based moral truth (i. e., no human wants to be cooked and eaten because it is frightening, painful and inopportune, therefore from a sensual standpoint we universally deem the witch's intentions to be morally wrong).

Affirmation of the validity of the reader's emotional reaction to intentions portrayed in the text can be extended to the individual's emotional reaction to experiences from her own life, due not only to the fact that the former mirrors the latter, but that the former was in fact constructed of elements of the latter, through the gentle guidance of the fairy tale text. It is as if the fairy tale has taken the reader by the hand, guided her in linking emotion with memory, affirmed for her that this linkage is rightful, and thusly ushered her out of emotional chaos and into a place of self-acceptance. It is the fairy tale's textual guidance from a valorized position that has made such self-acceptance possible.

\subsection{Aesthetic reading for the changing of perspectives}

I began this paper by commenting on the distance between fairy tale reality and contemporary reader reality. Here, I will elaborate further on the effect of the transactional reading event between hierarchically disparate realities, and why this disparity is responsible for the changing attitude of the reader towards her own personal associations. As previously mentioned, the fairy tale, like the epic, has its origin in the "absolute past" which is given its hierarchical value over the present time by virtue of its distance from contemporary reality (Bakhtin 1981: 13). Although Bakhtin envisions the isolated, "utterly finished" world of the epic as two-dimensional compared to the world of the realistic novel, when we apply his points about epic to the fairy tale genre, the same characteristics which contributed to its flatness appear to be precisely what makes fairy tales an appropriate medium for drawing personal associations up to a hierarchically higher position in the reader's regard, such that the reader might accept and even revere rather than condemn them.

When we perform transactions between associations from our own lives and textual events of the distant, "absolute past," we become aware that we have established an intimate connection with something of a higher valued category, something to be revered simply because of its age and intangibility (Bakhtin 1981). In combination with our awareness that the truths depicted in the fairy 
tale cannot be altered or disputed, we also pull our own associations and experiences into moral alignment with those fairy tale truths, and cease to dispute the validity of those emotional-cognitive fusions. In short, to return to the example of the Hansel and Gretel reader, she accepts her anger towards her overbearing mother, as she has developed the understanding that it comes in response to the natural desire of all children to achieve independence and separation from one's parents. Such an explanation validates the problematic emotion for the reader by revealing its sensually driven purpose.

I have discussed the particularly transformative influence of the sense of moral affirmation gleaned in the dual response process, but in addition to affirmation, a vast number of other senses remain possible, not all of which will necessarily lead to the positively affirming re-narration and harmonious integration of personal memories. These other natures of response do, however, still serve valuable transformative purposes, further strengthening the general case for transactional theory as the basis of reader transformation. One of these transformations is the shifting of critical perspectives towards cultures with which readers are unfamiliar, a goal for which many teachers and researchers have opted to use multicultural literature. Cai (2008) responded to critics of Rosenblatt's theory who deemed it unsuitable for teaching multicultural literature due to the fact that the personal, aesthetic responses of students seemed to reinforce their own misunderstandings and prejudices of unfamiliar cultures just as frequently as enhance understandings of them. Where Rosenblatt claimed that literature was a valuable tool in "aiding us to understand ourselves and others" (1982: 276), critics disagreed, saying that aesthetic readings allowed the personal interaction with literature to stand in the way of "correcting" prejudiced perspectives on multicultural literature. As Cai (2008) noted, these critics have simply misunderstood transactional theory. They have assumed that the text itself carries the necessary meaning for enhancing understanding of unfamiliar cultures, and that this meaning must be instructed first and foremost, before any personal, ideological associations are allowed to stand in the way of it. As Rosenblatt (1982) has explained, the meaning gleaned from a text arises from a synthesis of personal associations and textual guidance, therefore the assumption of Rosenblatt's critics that some meaning resides in the multicultural text independent of the reader is merely a projection of their own evoked meanings onto the texts. Rosenblatt's (1982) response supports the general idea of personal transformation through transaction with literature, as she explains her stance that aesthetic reading, rather than being a block to critical reading, is in fact the basis of critical reading. Much like the self-reflective process described in the theory of dual response streams, it is the critical, scrutinizing reflection upon one's own constructed meaning which 
provides the opportunity for any critical thinking at all. One cannot truly adopt a critical stance towards a text unless one has established a personal connection with it first, as genuine criticism is born of observing and questioning the validity of our initial perceptions and assumptions about what we have read (Cai 2008). A critical stance without a personal basis is merely the regurgitation of a stance which someone else, perhaps a teacher, has likely indicated as the ultimate, indisputable meaning residing within the work itself, independent of the reader's individual meaning-making actions.

Rosenblatt's insistence that aesthetic reading is not a barricade to critical reading, but in fact the first step to many other types of reading, including critical, indicates that a changed perspective begins, of course, with an initial, freely evoked perspective. When looked at in this way, it seems quite obvious that a perspective cannot be said to have changed without having some recognition of what it once was. The changed perspective must have a beginning, whether this beginning is an ideological stance towards an unfamiliar culture, or an uncomfortable stance towards a personal memory. The re-narration of such stances begins, then, with knowledge and understanding of the original stances themselves.

In the current paper, I will limit myself to the examination of one instance of changed perspective in particular, that of the nature of the emotional stance towards personal memories. Via transactional response, fairy tales exert a particularly influential magnetism in bringing to awareness and shifting an individual's emotional stance towards some aspect of personal life. Subsequent sections will elaborate on reasons for the valorization of the fairy tale genre, and the strength of its magnetism in re-narrating the reader's perception of personal reality. First, however, it is necessary to examine closely the previous theories laid out by psychoanalysts who have used fairy tales in their practices. This will then provide the basis for exploring new propositions of the means by which the exceptional, perspective-changing magnetism of fairy tale literature is born.

\section{Previous therapeutic applications}

The notion that fairy tale literature helps to resolve emotional conflict is not new. Its popularity begins with Bettelheim (1975), who elaborates on how enchantment by fairy tales functions as a catalyst for healthy emotional growth in young children, particularly those who have suffered emotional disturbances. Bettelheim offers, by way of a Freudian dissection of fairy tales into their 
symbolic elements, one possible theoretical route by which enchantment with traditional literature helps young children make sense of inner emotional conflict, and ultimately arrive at the next highest level of emotional maturity. Subsequent sections will discuss in further detail the theories of Bettelheim and contemporaries, examining the concept of self-reflection in fairy tale response as it was interpreted by these early psychoanalysts.

\subsection{Enchantment and children}

Although much remains to be celebrated of Bettelheim's theory of the therapeutic response to the fairy tale, Bettelheim himself, as former director of the University of Chicago's Orthogenic School, is not now universally treasured. He might be called polarizing, as evidenced by those who spoke out vehemently against him after his suicide at the age of 86 , and those who then passionately defended him. In spite of his clear passion for helping the children in his care grow into independent adults, his methods have come under harsh criticism. He was accused by some of striking children, mistreating employees, and making insensitive decisions regarding patients and their families (Rosenfeld 2000).

I criticize his violent behavior towards children in particular, but nevertheless find it essential to note that before arriving in Chicago, Bettelheim survived eleven months in Buchenwald and Dachau concentration camps. He was released in 1939 and immigrated to America, where five years later he was appointed institution director. Bettelheim was described by former students and employees as complex, and easily given to bouts of rage, impulsive comments and rash decisions (Rosenfeld 2000). Notably, all of the behaviors described are characteristic of people suffering from post-traumatic stress (Courtois 2004). To what degree Bettelheim himself suffered emotional trauma as a result of his incarceration is unknown, but the fact remains that concentration camps are places that destroy identities not only during incarceration, but long thereafter. Such destruction of the personality due to emotional trauma is often envisioned as a disintegrated or fractured personality, in which many psychological barriers exist between memories and aspects of personality in order to ensure successful coping with reality (Heisig 1977). It is fitting then that Bettelheim's theory of how children process fairy tales depends heavily on his idea that the integrated personality is something children have not yet achieved. Bettelheim in essence proposes that being emotionally integrated is the opposite of being infantile (Schopler 1998).

Furthermore, in his early writing about his experiences in Buchenwald and Dachau, Bettelheim notes that he witnessed fellow inmates developing "types of 
behavior which are characteristic of infancy or early youth" (Bettelheim as cited in Kidd 2005) as a result of severe abuse, deprivation and emotional stress. The notion of the disintegration of the adult personality to infancy, when considered from the point of view of the trauma psychologist, gives us a basis for Bettelheim's concept of the child's mind as reader. Bettelheim saw children as not yet integrated, in the same way that he saw his fellow Buchenwald and Dachau inmates as disintegrated. His theory of interpreting fairy tales, then, focuses entirely on the individual, and not social, act of personality integration as supported by reading fairy tales. In some respects, such as its focus on language-based personality integration, Bettelheim's theory has a firm foundation, however it becomes outdated in its strict adherence to the Freudian principle of projection onto symbols in literature, a concept he claimed was effective only for infantile readers of fairy tales, not adults.

Nevertheless, Bettelheim demonstrated a supremely forward-thinking position in basing his theory of emotional well-being on language and literature. In doing so, Bettelheim spanned the disciplines of psychoanalysis, literature, education and anthropology and brought them together for the common purpose of shedding light on the concept of meaning as it is made by human beings. We would do well to remember that Bettelheim conducted his research from within the Department of Education at the University of Chicago (as opposed to the Departments of Psychology, Psychiatry, or Psychoanalysis) and capitalized hugely on a university climate which, in that era, was receptive to departments sharing ideas and strengthening each other as a result (Szajnberg and Bettelheim 1992). In spite of those aspects of his theory which have now been rejected, his pioneering efforts to bring many disciplines together at the intersection of language and well-being must not be overlooked, and may be used as the basis for an expansion of his ideas into a theory which applies not only to children, but to any readers in need of personality integration. As Bettelheim himself knew, adults are certainly not immune to the personality regressions caused by emotionally overwhelming events.

\subsection{Expanding the applications of enchantment}

With his assumption that infancy denotes a lack of integration, it follows that Bettelheim (1975) was adamant about the fairy tale being completely inapplicable to the adult imagination. By that assumption, he seemed also to assume that all adults possess integrated personalities, but anyone who has ever known mental illness in an adult has seen that personalities do not always integrate successfully, nor do they always remain well integrated once having 
become so. As Heisig (1977) notes, in denying the possibility of applying his theory to adults, Bettelheim seems to prematurely close himself off from expanded applications of it. Bettelheim himself observed in his "Individual and Mass Behavior in Extreme Situations" (as cited in Kidd 2005) that extreme deprivation seems to result in disintegration of personality, but failed to apply his ideas about personality integration to all personalities which might be in need of support. If fairy tales work to integrate the personality of the child, might they not also then work to reintegrate the personality of the adult who has suffered a regression? Not only does Bettelheim (1975) leave adults out of his examinations, he goes so far as to explicitly identify them as a population on whom the enchantment of fairy tales is totally lost. Had Bettelheim been willing to see his own theory as a starting point, rather than a rigid process, he might have allowed it to transform into something more widely applicable.

Heisig (1977) notes other cornerstones of Bettelheim's theory that further evidence an unwillingness to see beyond its innate limitations. Bettelheim's theory focuses heavily on the notion of projection onto symbols in literature, that is, the "externalization" of inner conflict in a controlled, healthy manner (Heisig 1977: 102). This happens, as Bettelheim describes it, only in an individual, private way. But by making the process of integration solely private, Bettelheim "overlook[s] the social context whereby a story relocates an individual in the heroic ideals of a common past" (Heisig 1977: 103). To consider the role of the social context of fairy tales in the reader's response opens up a number of channels that may reveal more complex processes of literary response than projection. Bettelheim (1975) does not mention the historical origin or socio-historical propagation of the tales except to say that any evidence of religious or mythological origin in the tales would be lost on the young reader, which is likely true, but limits the potential effect of such knowledge to those who are well versed in the history of folklore. Folklorists and memeticists have argued that the "enchantment" born from such origins is not dependent on conscious, factual knowledge of them, but on patterns in the human brain which make certain stories ideal for treasuring and imitating, to be later treasured and imitated again in a cyclical process (Dawkins 1989; Zipes 2006). If what memeticists have argued is true, factual awareness of the origins and history behind a tale is not necessary in order for it to have some emotionally integrating effect on the reader. These socio-historical elements of fairy tale dissemination over time may be key features of a literary response process which is uniquely exemplified in readers of this genre.

Heisig (1977) also takes issue with Bettelheim's stance towards the "higher morality" found only in fairy tales, and their ability to instruct readers in the ways of ethical behavior. Recall that in previous sections of this paper, 
I demonstrated that the transactional theory of literary response might serve as a basis for self-reflective thought in readers. According to the model I have proposed, the integration of the personality is achieved through a process of affirmation of one's moral principles, an affirmation which is permitted and supported by a number of key features unique to the fairy tale genre. One of these features was fairy tales' treatment of morality through the depiction of characters' social behavior. Bettelheim (1975) notes that the "polarities of character" found in fairy tales are instrumental in providing ethical models for young children, although he cites the simplicity of such polarities as that which allows the child to easily comprehend the difference between the two. While Bettelheim (1975) insists that good and evil are always highly polarized and separated in the fairy tale (and for this reason, constitute a morality which is unsullied and therefore "higher"), Heisig (1977) disagrees, citing many instances of ambiguous morality in fairy tale characters. Fairy tale characters, Heisig claims, cannot effectively model morality for readers if their own moral directions are not uniform throughout the text.

I would urge both Bettelheim and Heisig to take their arguments a step further, into the realm of transactional theory, which proposes that meaning from a text is made from momentary transactions between reader and textual symbols (Rosenblatt 1978). The key word here is momentary. When meaning is made in moments of interaction with a text, whether good and evil remain uniformly polarized throughout the entire story could very well be inconsequential. We may see readers interacting with symbols in a text to create meaning which has its basis in a particular moment, but does not necessarily consider the overall plot trajectory. There is not necessarily an insistence from the reader that she who begins the story as good, finishes it the same way, or remains that way throughout. This ambiguous morality found in some fairy tales does not hinder our ability to make significant meaning from them. Furthermore, not every reader can be assumed to find every textual symbol throughout the fairy tale relevant. Certain symbols will of course elicit different strengths of personal association, based on the individual experiences of the reader. Again, Bettelheim's strict adherence to the system of projection onto symbols he has created blinds him from seeing that meaning can also be made momentarily, not only as a reflection on a whole.

Heisig (1977), in response to Bettelheim, also does not consider the transactional potential of each unit of meaning made within fairy tales and so deems their treatment of morality useless, when in fact the morality in fairy tales may be called "higher" not because of unsullied polarization, but because of its treatment of itself as universally, indisputably true (Jolles 1972). Heisig himself mentions, but does not seem to realize the significance of the fact that "although these stories are unreal, they are not untrue" (1977: 73). The absolute moral truth 
to which Heisig refers can easily be realized both by children and adults, and sets the stage for an expanded theory of the uses of enchantment.

\subsection{Enchantment and adults}

Dieckmann, a contemporary of Bettelheim, undertook an expansion of Bettelheim's theory in 1978 (originally publishing his findings in German as Gelebte Märchen), and with Bettelheim's blessing, as Bettelheim himself wrote the forward for the book. Dieckmann (1986) described similar processes to Bettelheim involving the use of fairy tales as tools for resolving emotional conflict, this time in adults. Dieckmann's work, much like Bettelheim's, merely suggests that a certain degree of transformation of the self must be triggered by the fairy tale, but fails to consider the patient's relationship with literature in depth as a system of dualistic response streams functioning to allow self-reflection to take place. Nonetheless, his work supports the idea that fairy tales are useful in contemporary clinical settings, and in doing so becomes part of the foundation which now allows us to view his case studies in light of transactional reader-response theory.

In short, Dieckmann describes the process of meaning-making from fairy tales in adults as the "casting [of] a bridge between two realms", these two realms being the conscious and the unconscious (1986: 17-18), and like Bettelheim, Dieckmann's analysis centers around bridging these realms by means of symbols which externalize inner conflict, bringing the patient from a place of emotional chaos to a place where treatment can begin. His patients selfidentified their "favorite" fairy tales from childhood and used elements from the tales in guided discussion to deal with neuroses which were hindering their ability to live responsible adult lives. While Bettelheim (1975) explicitly states that the elements of a fairy tale which correspond to externalized emotional conflict must never be pointed out to the child lest they be rendered ineffective, Dieckmann took a different approach with adults. After asking patients to identify their own favorite tale, he explicitly pointed out where their dreams and neuroses overlapped with fairy tale symbols. He even asked some patients to compose fairy tales of their own, demonstrating a recognition which Bettelheim did not seem to have of fairy tales as units of culture, significant in all expressions, not only as original, unchanged pieces of literature. Dieckmann's (1986) work expands on Bettelheim's theory in that he eliminates some outdated assumptions and begins to consider the socio-historical origins of the literature. His case studies are a valuable follow-up to Bettelheim's work because they show where fairy tales can be used not just for integrating the 
infantile personality, but also for re-integrating personalities which have been fractured. In Dieckmann's work, we see Bettelheim's theory of the therapeutic fairy tale strengthened by evidence of its successful application to a new population.

Additionally, the process of self-projection onto symbols in literature contains no element which reserves the uses of enchantment for fairy tales alone. Perhaps these symbols are more pronounced due to simplicity of presentation in fairy tales (Bettelheim 1975), but this certainly does not reserve the phenomenon of projection for fairy tales. The unique process of meaning-making which gives rise to higher emotional maturity as a result of the literature being a fairy tale must be spurred on by some element which pertains to the traditional literature genre, and this model of genre alone. If psychoanalysis can be applied to any genre of literature, clearly it is possible that additional elements are present in the interaction between reader and fairy tale. We may begin our discussion of those elements, which I will call not the uses, but the roots of enchantment, by examining the tales from social and historical standpoints. In each case, I will explain how these roots of enchantment bring about the affirmation of moral uprightness in readers, thus giving the self-reflective, transactional reading experience the ability to shift the reader's perception of her own reality. In this way I will attempt to explain the process behind that fairy tale enchantment which has, until now, been treated as a given.

\section{The roots of enchantment}

So far, we have observed what fairy tales do, which acts as a suitable starting point for theorizing why they do this, and how. Transactional theory provides the explanation of dual literary response streams, which set the stage for selfreflective thought in readers. There are then two modes, temporal and moral in nature, which give that self-reflection the distinct flavor of affirmation. These modes act to valorize the fairy tale genre as a whole, giving it and its messages a higher status than the current reality. It is this hierarchically higher reality with which fairy tale readers transact, constructing its meaning composed of their own associations, this time in a form which demands high reverence and unquestionable belief in its validity. The construction of a higher reality out of personal experiences then results in hierarchically raised perceptions of personal memories, and acceptance of their corresponding emotions. The ultimate result is an emotional-cognitive fusion which has now been accepted by its owner, and can sit harmoniously integrated within the overall narrative of the 
reader's life. I have already discussed Bakhtin's (1981) theory of temporal valorization of genre, which facilitates changes in emotional perspectives based on the hierarchical disparity between two colliding realities. Below, I will expand on the moral mode of genre valorization, which also functions to place the fairy tale genre on its pedestal, and allow the self-reflective process to result in raised perceptions of the self.

\subsection{Moral valorization: Naïve morality}

Rooted within any mode of genre valorization is the necessity that individuals continually find the fairy tale relevant. After all, in order for fairy tales or any literature to propagate, relevance to the individual must be determined over and over again. What makes the fairy tale psychologically appealing to the individual? What gives her the belief that what she reads is unquestionably true? The answer lies in fairy tales' ability to respond directly to issues of personal injustice, and in particular concerns the high value given to a response which comes from a distant reality.

We have already seen that one feature of the fairy tale which sets it in its own category, vastly different from realistic fiction and the modern novel, is that the reality portrayed in the fairy tale does not exist alongside our own current social reality. Fairy tale settings, characters and events are unlike the ones we encounter in our daily lives, and if comparisons are to be drawn, some exaggeration is necessary. Fairy tale reality, unlike the reality depicted in realistic fiction, is an impossibility. It is a reality wherein horses can fly, cats can speak, and meeting conniving wolves, trolls and witches while walking through the forest is not an uncommon occurrence. Fairy tale reality is of a different category, one which has, over time, developed a different value than our own (Bakhtin 1981).

As it depicts images of a reality distant from our own, the fairy tale holds great allure. This is not unlike what we see in the general human interest in and appreciation for art (literature included). Whether it is through painting, sculpture, dance, music, fiction or poetry, displays of art offer an alternative way of viewing existence which contrasts our established, habitual ways, and subsequently delights, comforts, entertains or even enrages us. Art in general has forever enthralled us with its ability to take us by the hand and guide us through a completely new and unfamiliar way of viewing the human existence we have come to consider mundane.

Still, even when placed among other categories of art, fairy tales hold a unique status at once magical, enchanting, and for some, healing. One has only 
to hear the descriptive phrase “... like something out of a fairy tale" to be reminded of the fact that culturally and socially, we hold the fairy tale in high regard. In this respect, fairy tales still occupy a position which other artistic media cannot fill. In seeking the source of this enchantment by transaction with alternate reality, I will explore the ideas of Dutch scholar Jolles (1972), whose basic assumption about human beings with regard to the fairy tale is that they are all of a moral disposition and through the sensual, natural world develop a naïve understanding of morality based on that which gives them pleasure. Nature is therefore what informs humans of what is moral or immoral based on what is lacking, and what produces harmony (Jolles 1972). Jolles explains that naïve morality must be called "instinctual" in human beings, that the judgment it activates is the purest ethical judgment of which we are capable, and that

[i]f we now determine our form [of the fairy tale] from this perspective, then we can say that a form is present in the fairy tale in which incidents ... are or the course of things is ordered in such a way that it fully corresponds to the demands of naïve morality, in other words, to our absolute instinctual judgment of what is good and just. As such the fairy tale stands in sharpest contrast to what we in the world are accustomed to calling actual events. The course of things in reality corresponds extremely rarely to the demands of naïve morality, or it is mostly unjust. In opposition, the fairy tale confronts the world of "reality" because this world of reality is not the world which confers values on a general valid way of life. It is a world in which the incidents contradict the demands of naïve morality, a world which we naively experience as immoral. One can say here the preoccupation [of the fairy tale] has a double effect: on the one hand, the preoccupation grasps and holds on to the world negating it as a reality which does not suit the ethics of the events. On the other hand, the preoccupation affirms another world in which all the demands of naïve morality are fulfilled. (Jolles in Zipes 2012: 13-14)

Jolles shows the world of the fairy tale to be a striking counter-world, creating a set of images which speak to us particularly in those difficult moments when it helps us to be shown a world in which our concept of what is good and fair is confirmed. By the same token, the fairy tale world also affirms for us that whatever injustice we happen to be experiencing in the actual events of our lives, we are not wrong to consider it an injustice. Our own judgment of that which is fair is thusly strengthened and supported by the alternate fairy tale reality.

If in seeking art one seeks an alternate reality, fairy tales seem to offer the starkest contrast to actual events a reader can possibly find. With the driving force behind such a quest for art being harmony in a world in which the demands for naïve morality are not met, this force is remarkably strong, and even instinctual, as Jolles (1972) suggests. Furthermore, the fairy tale offers not 
simply an alternative to the world in which the demands of naïve morality are not being met, but the precisely constructed, perfected counter-world to that (Zipes 2012). For someone who feels great pain due to the injustices experienced living amidst immorality, the reality presented in the fairy tale is an answer to prayers, a dream come true. The fairy tale appears to tell the absolute truth where our human companions may not.

If we consider that the appeal of fairy tales as simple story structures is linked to their ability to deliver that which we are not seeing in our own realities, then it is very easy to see why a special, magical, healing quality has been bestowed upon them, and all the more so for those whose instinctual demands with regard to morality are not being met. This holds true for any reader who experiences emotional pain as a result of some form of injustice, as it is these painful associations which determine the high relevance of the tale and constitute the building blocks of the meaning making process. Before they are ever valorized socially, fairy tales are valorized privately, based on the sensual, ethical needs of meaning-making Homo sapiens.

\section{Conclusion}

Even when we are not consciously aware of the distance between actual and literary realities during the reading experience, the effect of this distance is tangible. When fully absorbed in the reading of a distant reality, we feel as though our thoughts have constructed a world which we could not possibly inhabit, a world which seems to have existed "once upon a time" but which does not sit at any identifiable point on the same time line on which we now find ourselves. In developing a more complex model of the manner in which meaning of the "absolute past" is constructed with elements of our own experience, we see major differences between constructing meaning from a reality which exists alongside our own, and constructing meaning from a reality which presents us with a vast hierarchical disparity. The collision of two hierarchically disparate realities is of great force (as one can imagine that they have had more distance over which to accelerate before colliding) but as Zipes (2012) reminds us, collisions do not destroy, but rather disrupt the mechanisms and structures of things. The fairy tale seems to exert a strange and powerful magnetism in these collisions, one which piqued the interests of psychoanalysts in the 1970s and gave fairy tales something of a position in clinical settings. Theories of the therapeutic response to fairy tales began with a focus on symbols in text in the conceptual sense, onto which children would project internal conflict, as 
Bettelheim (1975) hypothesized, and thusly play out their problematic fantasies in an externalized, healthy fashion. While Bettelheim set the stage for the idea of literature as a catalyst for personality integration, in the end he did not describe a process which could truly be called exclusive to fairy tales, and so provided an incomplete explanation for the magnetism of the genre. His theory of the therapeutic literary response, had it been enhanced with elements of Rosenblatt's (1978) transactional theory, might have capitalized on a mechanism of self-reflection at work in readers.

As we have seen, transactional reading is a crucial prerequisite to the selfreflective process. It scaffolds a rationality of mind in fusing thoughts with emotions, and facilitates a secondary, contemplative response of the reader to this fusion. In the case of fairy tales, the secondary response is often accepting in nature due to the fact that the validity of the resulting emotional-cognitive fusion is indisputable, made so by temporal distance between realities (Bakhtin 1981) and a treatment of ethical principles based on the sensually based moral needs of human beings (Jolles 1972). As a result of these modes of valorization, each one unique to the fairy tale genre, the emotional-cognitive fusion brought about in transactional reading can be accepted in the self-reflective reading process with great faith in its validity. The end result, simply put, is an ability to reflect on one's own life with acceptance of one's own memories. Where previously such problematic memories may have caused emotional discord, fairy tales facilitate that re-narration necessary for memories to be integrated harmoniously into the life narrative of the reader.

Looking beyond therapeutic settings, further implications for the proposed model of response are vast. An understanding of the process by which the validity of personal experience is affirmed can help educators identify other types of literature which might support the same response. After all, not everyone enjoys reading fairy tales, but a model of a process which is effective in integrating emotions could support the application of other genres of literature to readers in need of emotional support, just as a doctor prescribes different types of medication to different patients. Additionally, if we view the process in a more generalized light, studying the process of cognitive transformation through transactional reading has major implications for the study of encouraging critical thinking and response in classrooms, particularly in young children. Overall, the model suggests that literature is vastly more influential to human lives than the current credit we give it suggests, and proposes that literature may be a valid link between curriculum and mental health. Our strategy for educating the whole person may involve not the introduction of new elements into the classroom, but rather a reconsideration of that which is time-tested, and already in front of us. 


\section{References}

Bakhtin, Mikhail M. 1981. The dialogic imagination. Austin: University of Texas Press.

Beach, Richard. 1993. A teacher's introduction to reader-response theories. Urbana, IL: National Council of Teachers of English.

Bettelheim, Bruno. 1975. The uses of enchantment: The meaning and importance of fairy tales. New York: Vintage.

Cai, Mingshui. 2008. Transactional theory and the study of multicultural literature. Language Arts 85(3). 212-220.

Courtois, Christine A. 2004. Complex trauma, complex reactions: Assessment and treatment. Psychotherapy: Theory, Research, Practice, Training 41(4). 412-425.

Dawkins, Richard. 1989. Memes: The new replicators. In The selfish gene, 189-201. New York: Oxford University Press.

Dieckmann, Hans. 1986. Twice-told tales: The psychological use of fairy tales. Wilmette: Chiron. Heisig, James W. 1977. Bruno Bettelheim and the fairy tales. Children's Literature 6. 93-114.

Jack, Sarah J. \& Kevin R. Ronan. 2008. Bibliotherapy: Practice and research. School Psychology International 29(2). 161-182.

Janson, Gregory R. \& Margaret A. King. 2006. Emotional security in the classroom: What works for young children. Journal of Family and Consumer Sciences 98(2). 70-74.

Jolles, Andres. 1972. Formes simples. Paris: Éditions du Seuil.

Kidd, Kenneth B. 2005. Bruno Bettelheim and the psychoanalytic feral tale. American Imago 62(1). 75-99.

Miller, Alice. 1984. Thou shalt not be aware: Society's betrayal of the child. New York: Farrar, Straus, Giroux.

Rosenblatt, Louise. 1978. The reader, the text, the poem. Carbondale: Southern Illinois University Press.

Rosenblatt, Louise. 1982. The literary transaction: Evocation and response. Theory into Practice 21(4). 268-277.

Rosenblatt, Louise. 1983. Literature as exploration. New York: Modern Language Association.

Rosenfeld, Alvin A. 2000. Bettelheim revisited. Journal of the American Academy of Child and Adolescent Psychiatry 39(12). 1461-1463.

Schopler, Eric. 1998. Misleading metaphors of Bruno Bettelheim. PsychCRITIQUES 43(1). 19-21.

Szajnberg, Nathan M. \& Bruno Bettelheim. 1992. Educating the emotions: Bruno Bettelheim and psychoanalytic development. New York: Plenum Press.

Zipes, Jack. 1983. Fairy tales and the art of subversion: The classical genre for children and the process of civilization. New York: Wildman Press.

Zipes, Jack. 2006. Why fairy tales stick: The evolution and relevance of a genre. New York: Routledge.

Zipes, Jack. 2012. The irresistible fairy tale: The cultural and social history of a genre. Princeton: Princeton University Press. 